\title{
ESTIMATED AND EXPERIMENTAL RESEARCH OF SEPARATION PART OF SPP-500-1
}

Vera V. Legkostupova ${ }^{a}$, Alexandr V. Sudakov

St. Petersburg Polytechnic University Peter the Great, 195251 St. Petersburg, Russia

\begin{abstract}
This paper describes estimated and experimental research of the modernized separation part of SPP-500-1. The experimental research were conducted on full-scale machines on the unit No.4 of the Leningrad NPP. The results showed the effectiveness of modernization. The estimated research need for quantify modernization and development of recommendations when designing new models of MSR.
\end{abstract}

\section{INTRODUCTION}

In our country single-loop nuclear power plants (NPP) with boiling water graphite reactors of the RBMK-type and double-loop NPP with pressurized water reactors of VVER-type have been most developed. Turbine of these NPP are operating on saturated steam. One of the problems of such turbines is ensure the acceptable humidity in the flow passage of the cylinder low pressure (CLP), which can be provided only by external separation with steam reheating. The moisture separatorreheaters (MSR) is heat exchangers, combined with a separation device. They are designed for separation and reheat steam exhaust in the cylinder high pressure (CVP) of the turbine, and ensure permissible humidity steam on the blades of the last stages of CLP.

The separation device is arranged so that the shape of input and output manifolds pair is close to the wedge. For single-loop NPP with RBMK reactors used only smooth stainless steel pipes. Vehicles equipped with tanks for separator and drain which are located below the points of drain from MSR [1]. Drain from MSR is gravity. The construction of MSR for NPP with RBMK reactors are required minimum steam volume at maximum heat output, easy operation and maintenance, availability of washing and preservation, the ability to control the density and defect detection, etc.

Currently all the operating units with reactors RBMK-1000 on turbines K-500-65/3000 installed separators SPP-500-1 designed by ZiO. The design of this MSR is described in [2]. The main advantages of its construction: the separation device is assembled from separate separation blocks and reheating surface of each of the stage is partitioned and is assembled from separate vertical modules, which allows for repairs on MSR without stopping the unit. The main disadvantages of this design MSR are location of the separator above the heating surface and the lateral supply of wet steam is caused uneven distribution of steam by separating the blocks and bringing moisture through the separator to the heater, which resulted in fatigue failure of pipe wiring of heating steam and the tubes of the heating surface and reduce the effectiveness of superheating. This adversely affects the efficiency and reliability of turbines.

${ }^{\mathrm{a} C}$ Corresponding author: faith89@yandex.ru 
Great disparity in the distribution velocities and dynamic pressures and humidity in the MSR's separation blocks, is mainly related with design features of the organization of the steam flow in the input chamber. To reduce uneven distribution of steam flow through the separation units and improve the reliability and efficiency of steam separation at Leningrad, Kursk and Smolensk NPP was upgraded SPP-500-1. Modernization SPP-500-1 based on the replacement of domestic louver separation packages for louvered packages Powervane developed by the company Balcke-Durr (Germany). Also the traffic pattern pair in the input chamber, the location of the separation packages and system headers were changed. It is changing the design of a separation part of the turbine has provided improvement of working conditions louvered packages.

\section{EXPERIMENTAL RESEARCH}

For development of measures on modernization and assessment of their effectiveness it is necessary to make research. The most reliable results can be obtained when the research is made on full-scale vehicles. But not to mention their high cost, such studies are difficult to organize the necessary volume measurements. In this case, when the finished design and unsatisfactory results are obtained, it is difficult to make any significant changes.

Despite all the difficulties, in May - June 2010 were tested upgraded MSR at power unit No. 4 of the Leningrad NPP. During these tests was determined by the humidity of the heated steam for separation blocks and was the measured temperature of the heated [3,4]. The measurement results confirmed the expected effect of the modernization of the MSR:

- analysis of the data shows that in all four MSR moisture is distributed evenly around the perimeter of the apparatus, and the humidity is in the range $0,4 \div 0,6 \%$;

- obtained value of the temperature of the heated steam showed that the bimodal character of the approximating curves is due to the fact that different groups overheating modules have different length lines for supplying heating steam.

\section{ESTIMATED RESEARCH}

Another opportunity is training design on quite a large physical models. However, it also requires quite a long time and significant costs.

Therefore, the most appropriate (at least at the initial stage of development) is conducting computational research and variant analysis. Design for universal computational model adequately describing the processes taking place in the MSR. Such model will allow to determine all the parameters of the steam flow at any point in the input chamber and the separation blocks. First the calculations and analysis of the flow of the steam flow, the velocity distribution in which the separation units are explicitly connected with the geometric dimensions of the flow passage. By acting on the geometrical dimensions of the separation blocks changes the flow pattern of steam flow is achieved prior to its optimization.

The analysis model includes: determining values of local velocities of steam (at the entrance to the separation chamber and in the block before the blind, at the outlet of the separation blocks), spending a couple (on the separator and separation unit), the pressure loss in the separator. The method used to model separation part of SPP-500-1 before and after the upgrade. The work has built a threedimensional geometrical model of the separation part of SPP-500-1 to (Fig. 1) and after (Fig. 2) modernization, after which they were imported into the software package Ansys CFX, which is built of block-structured computational grid of the input chamber and the separator for further calculation of the flow in CFX-Pre and the processing of results of calculations in the subroutine in CFX-Post.

The result of the calculation is planned to obtain three-dimensional distribution of velocity vectors pair (evaluation of uniform distribution of steam in the separation of the blocks, the control of education reverse currents in the input chamber, the capture and movement of moisture through the separator is drained by steam). The obtained computational grid consists of more than 10 million elements hexahedrons, the smallest angle of the mesh node $18^{\circ}$, the size of the elements 4 to $200 \mathrm{~mm}$. 


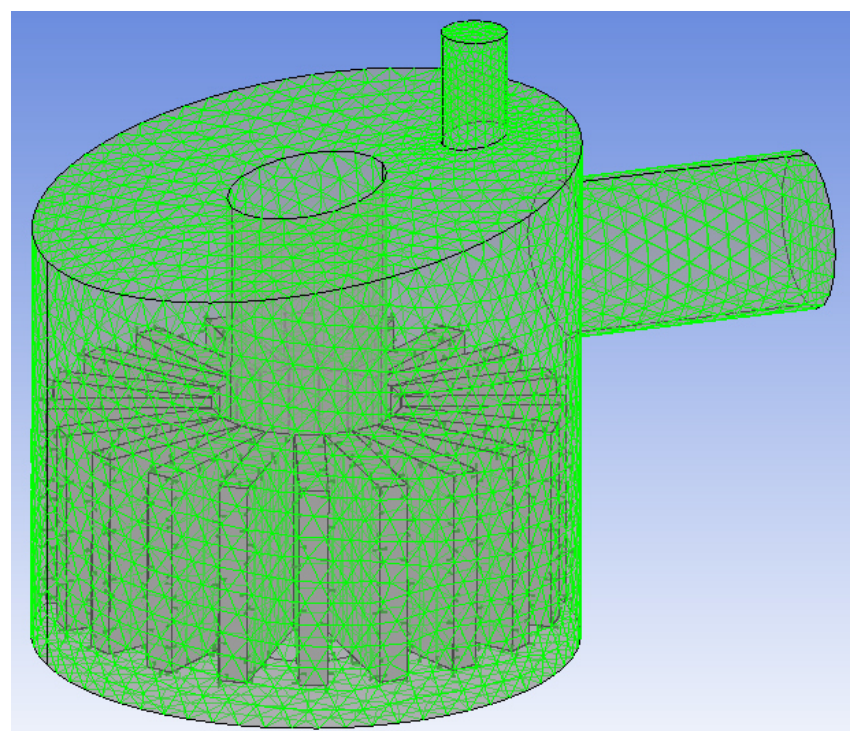

Figure 1. The geometric model of the separation part of SPP-500-1 before the modernization.

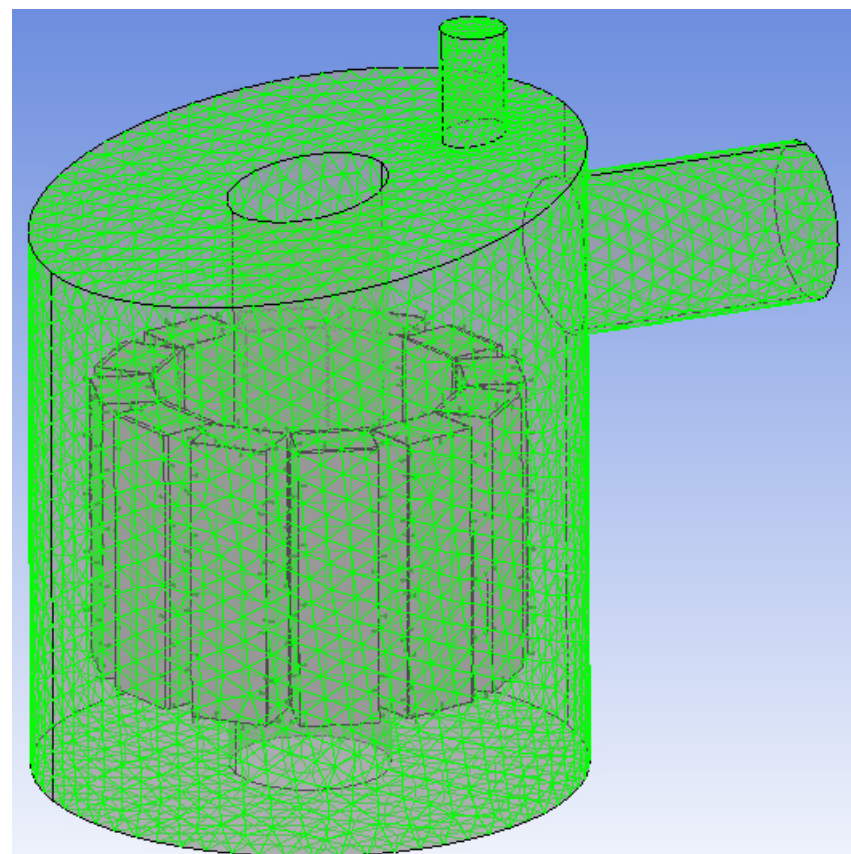

Figure 2. The geometric model of the separation part of SPP-500-1 after the modernization.

\section{Conclusion}

Organizing a uniform distribution of the steam flow on the separation of the blocks will make possible to achieve residual moisture in the pair after separator less than $1 . . .2 \%$, which corresponds to the design levels. The quality of the dried vapor and the organization of the evacuation of separate from the apparatus depends on reliable and safe operation of the MSR and the turbine as a whole. The issue of ensuring reliable operation of the MSR is relevant now. There are a large number of the recommendations until the new projects MSR structures that are still waiting for their implementation. 


\section{References}

1. Andreev P. A. The Moisture separator-reheaters for nuclear power plants with water cooled reactors / P. A. Andreev, L. N. Artemov, Bakanov A. F. [and others] // plant Engineering. 1977. No. 5. P. 22-24.

2. Sudakov V. A., B. S. Fokin Steam generators and heat exchangers of nuclear power plants. SPb.: NPO CKTI, 2005, 254 p.

3. Egorov Y. M. Tthe results of modernization of moisture separator-reheaters turbines in the fourth power unit of the Leningrad NPP / M. Y. Egorov, K. V. Sokolov, M. A. Blinov [et al.] / / Scientific and technical sheets SPbSPU. 2011. № 3 (130).- P. 263-272.

4. M. A. Kiseleva T. L. President The results of the tests of the modernized separator-superheater turbine K-500-65/3000 unit No. 4 of the Leningrad NPP / M. A. Kiseleva T. L. President, B. S. Fokin, M. J. white [and others] // Teploenergetika. 2012. No. 2.- P. 27-32. 